\title{
Spectrum of anomalies in Fanconi anaemia*
}

\author{
ANTHONY GLANZ AND F CLARKE FRASER \\ From the Department of Medical Genetics, The Montreal Children's Hospital; and the Department of \\ Biology and the Centre for Human Genetics, McGill University, Montreal, Canada H3A IBI.
}

SUMMARY The frequency of various anomalies was compared in probands with Fanconi anaemia and their affected sibs. As probands are usually ascertained because of a 'characteristic' array of physical anomalics, the frequencies of these specific anomalies may be overestimated in probands, whereas their affected sibs may provide a more accurate estimate.

The frequencies of growth retardation, skin hyperpigmentation, radial ray deformities, radial ray reduction deformities, hypogenitalia, and supernumerary thumbs were significantly lower in the affected sibs of probands than in probands. Since $25 \%$ of the affected sibs had no dysmorphic features, absence of dysmorphism is not sufficient to rule out the diagnosis.

Fanconi anaemia is an autosomal recessive disease that presents as a pancytopenia associated with a variety of congenital malformations. The haematological features of the disease are the result of bone marrow hypoplasia, with a subsequent reduction in all the cellular elements of the blood. The age of onset of the haematological problems is variable; they generally occur between the ages of 4 and 7 years.

The congenital malformations affect one or more systems, including the skeletal, ocular, auditory, renal, genital, and central nervous systems. Affected persons may have anomalies of all these systems or just some of them and no malformation is always present. This variation in the number and severity of the congenital malformations precludes the establishment of hard and fast diagnostic criteria on clinical grounds alone. In recent years, cytogenetic studies have demonstrated that affected subjects usually have an increased frequency of chromosomal breaks, even in the pre-anaemic stage, and thus the clinical diagnosis can now be confirmed by cytogenetic analysis. ${ }^{1}$

Since the diagnosis is more likely to be made in severe than in mild cases, the frequencies of specific malformations in probands in published reports will overestimate the true frequencies with which these anomalies occur. Statistical techniques using clustering methods are now being developed to circumvent this problem. ${ }^{2} 3$ However, in recurrent conditions, an easier and more practical approach to rectifying this bias is the analysis of the affected sibs *Publication 82.026 from the McGill University-Montreal Children's Hospital Research Institute.

Received for publication 19 February 1982. of probands. The rationale behind this approach is that the array of anomalies found in Fanconi anaemia probands will be influenced by the concept of what constitutes the syndrome and this concept will be strongly influenced by the description of the original cases, which are likely to be severely affected. Cases that do not conform sufficiently to this preconceived picture will not be diagnosed as Fanconi anaemia and will therefore not be included in any series. However, the affected sibs of index cases will provide a much more accurate representation of the phenotype, as they are included not because they fit the preconceived picture, but because they have a sib who does.

Fanconi's original description was of three brothers who suffered from anaemia, skin hyperpigmentation, microcephaly, genital hypoplasia, strabismus, and hyperreflexia. ${ }^{4}$ Hypoplasia of the radius and thumb and deafness were subsequently added to the list of malformations. ${ }^{56}$

This study presents evidence that some of the anomalies generally considered to be characteristically associated with Fanconi anaemia are in fact less frequent than supposed, and that no one feature is pathognomonic of the syndrome.

\section{Material and methods}

The files of the Department of Medical Genetics and published reports were searched for cases in which (1) adequate case descriptions were provided, and (2) the proband had at least one malformation relevant to Fanconi anaemia and either pancytopenia or an increased frequency of chromosomal breaks. 
These criteria allowed inclusion of 89 probands from published reports, five probands from our files, and 44 affected sibs of probands, all from published reports. In addition, five probands were identified with the clinical and haematological features typical of Fanconi anaemia, but with no increase in chromosome breakage. This group is considered separately, as they are all sporadic cases and more familial cases are needed before deciding whether they represent a variant of Fanconi anaemia with stable chromosomes or whether they are a distinct genetic entity.

Thus, 94 probands and 44 affected sibs were considered suitable for this analysis. In cases where the proband was not clearly identified, a judgement was made on the basis of the case history.

\section{Results}

\section{DESCRIPTION OF ANOMALIES}

The haematological course of the disease is invariably fatal and is characterised by poikilocytosis, anisocytosis, reticulocytopenia, thrombocytopenia, and leucopenia. ${ }^{7}$ The mean age of onset was 8.4 years old in the present series, the mean for probands being $7.9 \pm 5.2$ years and for non-probands $9.4 \pm 6.4$ years. Some cases have been reported where the anaemia did not start until the third decade of life. ${ }^{8-13}$ This variability cannot be attributed simply to genetic heterogeneity, as families exist in which one sib developed the pancytopenia at the usual age, and other affected sibs developed it only at a later age.

The skeletal anomalies encountered in Fanconi anaemia most commonly involve abnormalities of the hand and forearm. Hypoplastic, malformed thumbs are frequent findings ${ }^{6101214-36}$ and, interestingly, supernumerary thumbs are also seen. $5815163037-43$ One patient in the series was reported to have a supernumerary thumb on one hand and a dysplastic thumb on the other ${ }^{38}$ suggesting that this difference in expression does not represent genetic heterogeneity. The forearm anomalies consist of hypoplastic or absent radii. ${ }^{6} 8$ $172122272932343644-46$ Congenital hip dislocation is another malformation frequently seen. Other skeletal anomalies have been reported in Fanconi anaemia patients, but not consistently enough to be considered an integral part of the syndrome. These include ulnar dysplasia (2), osteoporosis (1), Sprengel deformity (2), Klippel-Feil anomaly (3), and clinodactyly (5).

The central nervous system can be involved in Fanconi anaemia. Microcephaly, mental retardation, and growth retardation are commonly seen. One patient in the series had hydrocephalus. ${ }^{22}$
Urogenital malformations are fairly common. Renal anomalies may include complete absence of one kidney, hypoplastic and/or malformed kidneys (usually horseshoe), ectopic kidneys, and double ureters. The genital malformations are hypogenitalia, hypospadias, and cryptorchidism. One interesting report describes a Fanconi anaemia patient with complete transposition of penis and scrotum combined with mild hypospadias. ${ }^{46}$

Microphthalmia and strabismus, either convergent or divergent, are the only ocular findings.

Hearing loss, usually mild, has been reported. ${ }^{6} 8$ 111226283134384247 Malformed ears have also been observed. Although no characteristic facies has ever been postulated for Fanconi anaemia, isolated reports of facial anomalies such as high arched palate, micrognathia, ${ }^{47}$ epicanthus, and facial asymmetry ${ }^{38}$ have been published.

The typical karyotype reveals chromosomal breaks or gaps in over $10 \%$ of cells. Recent studies indicate that these breaks may occur in a nonrandom fashion with some areas of certain chromosomes being more susceptible than others. ${ }^{48-51}$

\section{FREQUENCIES OF ANOMALIES}

The table shows the various anomalies seen in Fanconi anaemia and the frequencies with which they appear in probands and in affected sibs. As expected, most of the frequencies are higher in the probands than in the non-probands.

The most frequent finding (apart from the blood and chromosomal abnormalities which were almost

TABLE Characteristics in Fanconi anaemia in probands and non-probands.

\begin{tabular}{lll}
\hline & $\begin{array}{l}\text { Present in } \\
\text { probands }(\%) \\
(n=94)\end{array}$ & $\begin{array}{l}\text { Non-probands (\%) } \\
(n=44)\end{array}$ \\
\hline Growth retardation & 77 & $48^{*}$ \\
Skin hyperpigmentation & 73 & $57 \dagger$ \\
Combined radial ray deformities & 66 & $39 \dagger$ \\
Radial ray reduction & 55 & $36 \dagger$ \\
Hypogenitalia & 51 & $18 \dagger$ \\
Malformed thumb & 39 & 27 \\
Microcephaly & 37 & 25 \\
Renal malformation & 32 & 23 \\
Mental retardation & 29 & 20 \\
Cardiac murmur & 29 & 16 \\
Absent thumb & 22 & 13 \\
Supernumerary thumb & 16 & $5 \dagger$ \\
Microphthalmia & 14 & 7 \\
Hypoplastic/absent radius & 13 & 9 \\
Hearing loss & 13 & 5 \\
Hypospadias & 11 & 4 \\
Ear malformation & 11 & 11 \\
Congenital hip dislocation & 9 & 5 \\
Cryptorchidism & 7 & 63 \\
Male & 59 & 25 \\
No malformations & - & \\
\hline
\end{tabular}

$* \mathrm{p}<0.001$ using $x^{2}$ test. $+\mathrm{p}<0.05$. 
universal) is growth retardation. Seventy-seven percent of probands manifested this feature, whereas only $48 \%$ of non-probands had it. This difference was statistically significant by the $\chi^{2}$ test $(p<0 \cdot 01)$. Other anomalies in which there were significant differences between probands and non-probands were skin hyperpigmentation, combined radial ray defects, radial ray reduction deformities, hypogenitalia, and supernumerary thumbs. Only $57 \%$ of non-probands had hyperpigmentation of the skin, $39 \%$ had radial ray defects, $36 \%$ had radial ray reduction deformities, $18 \%$ had hypogenitalia, and $5 \%$ had supernumerary thumbs.

What was surprising was that many anomalies generally thought to be an integral part of Fanconi anaemia were not found as frequently as expected. Most prominent in this group are absence of the radius, which was found in only $13 \%$ of probands and $9 \%$ of non-probands, and absence of the thumb, found in $22 \%$ of probands and $13 \%$ of non-probands. However, when all the radial ray defects are combined, $66 \%$ of probands and only $39 \%$ of nonprobands were affected. Other anomalies that occurred with a fairly low frequency were missing or malformed kidneys, microcephaly, mental retardation, hypospadias, cryptorchidism, and congenital hip dislocation. A finding of particular practical significance was that $25 \%$ of the non-probands had no congenital malformations. Their only signs of the disease were the pancytopenia and the chromosome breaks. Thus, the absence of dysmorphic features does not rule out the diagnosis of Fanconi anaemia in an anaemic patient with chromosome breaks.

All 44 of the non-probands in this series whose chromosomes were investigated exhibited an increased rate of chromosomal breakage. Three probands from published reports ${ }^{385153}$ and two from our files had pancytopenia with normal chromosomes. They were all isolated cases. All of these patients had skin hyperpigmentation, while growth retardation, microcephaly, and radial ray reduction deformities were found in three of them.

\section{GENETICS}

Fanconi anaemia is an autosomal recessive disease, with a recurrence risk of 1 in 4 . Methods of carrier detection are now being developed using cytogenetic techniques after challenge with a mutagen in culture. ${ }^{47}$

Earlier studies reported a distortion in the sex ratio, with more males than females being affected in a ratio of $3: 2 .{ }^{21}$ Our series also showed a preponderance $(82: 54)$ of affected males, significantly different from 1 by the $\chi^{2}$ test $(p<0.02)$. When broken down into probands and non-probands, the sex ratios do not differ significantly from unity
(1.43 for probands, 1.75 for non-probands). Clearly, the excess of males is not the result of a tendency to diagnose the disease in males more often than in females, since this would lead to a higher sex ratio in probands than non-probands.

\section{Discussion}

The genetic defect that Fanconi originally described is a pleiotropic condition in which the two most consistent markers are the haematological and cytogenetic anomalies. However, the age of onset of the anaemia is variable and it is possible that chromosome breaks are not always present. As the table illustrates, the range and frequencies of the various other associated anomalies are also diverse.

The practical implications of these findings are important. For instance, if a child presents with hypogenitalia, microcephaly, and an unusually high number of cells with chromosomal breaks, but no anaemia, should he be considered as a case of Fanconi anaemia, or should the diagnosis rest more strongly upon the haematological findings? It is possible that the malformations seen are not always a harbinger of pancytopenia. Because no specific biochemical abnormality has yet been isolated, the diagnosis must still be based on the clinician's perspective of what Fanconi anaemia is and whether his patient fits well enough into that classification.

The phenotype of Fanconi anaemia is probably the result of a single genetic mutation that may or may not produce a wide range of anomalies in affected persons. Estren and Dameshek reported two families in which aplastic anaemia was the only consistent anomaly ${ }^{54}$ Interestingly, both probands had genital problems (one had an absent left testis and the other had cryptorchidism), but the five affected sibs had normal genitalia. These families demonstrate that the anaemia need not be associated with congenital malformations, as in the majority of cases. Another example is a report of two brothers with the typical hasmatological disease and chromosomal breaks but no other associated anomalies. ${ }^{1}$

The family reported by Berger and co-workers is also an unusual variant of Fanconi anaemia. ${ }^{15}$ They described a father with a malformed thumb whose daughter had Fanconi anaemia. It is possible that a dominant gene with variable expressivity produced the Fanconi-like malformation seen in the father and the full syndrome with anaemia in his daughter. More probably, the anomalies seen in the father are the result of the occasional heterozygote expression of the Fanconi gene. Another less likely possibility is that the father's malformations are unrelated to those of his daughter. 
An unusual sub-group of patients are the five probands who do not have unstable chromosomes. These patients could represent a different gene mutation not affecting the chromosomes, or the same mutation with chromosomal anomalies not detectable by current cytogenetic methods, or the lack of apparent chromosomal instability could simply be another example of variable expression of the Fanconi gene, as is the case with the other malformations.

In summary, analysis of the sibs of probands provides a more representative sampling of the frequencies of anomalies found in Fanconi anaemia than the probands, and demonstrates that the frequencies of many of the anomalies have been overestimated. This is especially true of radial ray dysplasia, generally considered to be the most characteristic feature of this disease, but occurring in only $39 \%$ of non-proband patients. Furthermore, the diagnosis of Fanconi anaemia should not be ruled out in an anaemic patient with chromosome breaks, even in the absence of dysmorphic features.

\section{References}

1 Hirschmann RJ, Shulman NR, Abuelo JG, Whang-Peng J. Chromosomal aberrations in two cases of inherited aplastic anemia with unusual clinical features. Ann Intern Med 1969;71:107-17.

2 Preus M. The numerical versus intuitive approach to syndrome nosology. Birth Defects 1980;XVI:93-104.

3 Opitz JM, Herrmann J, Petterson JC, Bersu ET, Colacino S. Terminological, diagnostic, nosological and anatomical-development aspects of developmental defects in man. Adv Hum Genet 1969;9:71-164.

4 Fanconi G. Familiäre infantile pernizosaaritige anämie. $Z$ Kinderheilkd 1927;117:257-80.

3 Dawson JP. Congenital pancytopenia with multiple congenital anomalies (Fanconi type). Pediatrics 1955;15: 325-33.

6 Estren S. Suess JF, Dameshek W. Congenital hypoplastic anemia associated with multiple developmental defects (Fanconi's syndrome). Blood 1947;2:85-93.

7 Bloom GE. Disorders of bone marrow production. Pediatr Clin North Am 1972;19:983-1008.

8 Schroeder TM, Tilgen D. Krüger J, Vogel F. Formal genetics of Fanconi's anemia. Hum Genet 1976;32: 257-88.

9 Rohr K. Familial panmyelophthisis: Fanconi syndrome in adults. Blood 1949;4:130-41.

10 Skikne BS, Lynch SR, Bezwoda WR, et al. Fanconi's anaemia with special reference to erythrokinetic features. $S$ Afr Med J 1978;53:43-50.

11 Swift M, Zimmermann D, McDonough ER. Squamous cell carcinomas in Fanconi's anemia. JAMA 1971;216: 325-6.

12 McDonough ER. Fanconi anemia syndrome. Arch Otolaryngol 1970;92:284-5.

13 McCabe CME, Lange RD, Crosby CWH. The coincidence of hemoglobin $\mathbf{J}$ and Fanconi's syndrome of hypoplastic anemia with hypoplasia of the spleen in a young man. Am J Med 1957;23:329-32.

14 Bargman GJ, Shahidi NT, Gilbert EF, Opitz JM. Studies of malformation syndromes in man. XLVIII: disappearance of spermatogonia in the Fanconi anemia syndrome. Eur J Pediatr 1977;125:163-8.

15 Berger R, Bussel A, Schenmetzler C. Somatic segregation and Fanconi anaemia. Clin Genet 1977;11:409-12.

16 Berger R, Bussel A, Schenmetzler C. Anomalies chromosomique et anémie de Fanconi. Nouv Rev Fr Hematol 1975;15:539-50.

17 Van Buchem FSP, Samson N, Nieweg HO. Familial pancytopenia with congenital abnormalities (Fanconi's syndrome). Acta Med Scand 1954;149:19-29.

18 Hayashi K, Schmid W. The rate of SCE parallel to spontaneous chromosomal breakage in FA and to trenimon-induced aberrations in human lymphocytes and fibroblasts. Humangenetik 1975;29:201-6.

19 Hill RD. Familial cancer on a Scottish island. $\mathrm{Br}$ Med J 1976;2:401-2.

20 Jones R. Fanconi's anemia; simultaneous onset of symptoms in two siblings. J Pediatr 1976;88:152.

21 Juhl JH, Wesenberg RL, Gwinn JL. Roentgenographic findings in Fanconi's anemia. Radiology 1967 ;89:646-53.

22 Kunz H. Hypoplastic anemia with multiple congenital defects (Fanconi's syndrome). Pediatrics 1952;10:286-91.

23 Levy W. Aplastic anemia in siblings with multiple congenital anomalies (the Fanconi type). J Pediatr 1952; 40:24-41.

24 Minage H, Steinbach HL. Roentgen appearance of anomalies associated with hypoplastic anemias of childhood: Fanconi's anemia and congenital hypoplastic anemia (erythrogenesis imperfecta). AJR 1966;97:100-9.

25 Nilsson LR. Chronic pancytopenia with multiple congenital abnormalities (Fanconi's anaemia). Acta Paediatr Scand 1960;49:518-29.

26 Pochedly C, Collipp PJ, Wolmar SR, Suwansirikul S, Regvani I. Fanconi's anemia with growth hormone deficiency. J Pediatr 1971 ;79:93-6.

27 Prindull G, Stubbe P, Kratzer W. Fanconi's anaemia. I. Case histories, clinical and laboratory findings in six affected siblings. $Z$ Kinderheilkd $1975 ; 120: 37-49$.

28 Silver HK, Blair WC, Kempe CH. Fanconi syndrome. Multiple congenital anomalies with hypoplastic anemia. Am J Dis Child 1952;83:14-25.

29 Higashi O, Koseki E, Higuchi M. A case of Fanconi's syndrome with study of peroxidase activity of the erythron. Arch Dis Child 1953;28:359-62.

30 McDonald R, Goldschmidt B. Pancytopenia with congenital defects (Fanconi's anaemia). Arch Dis Child 1960;35:367-72.

31 Grislain JR, Lemoine P, Mertouzet N. Nanisme type Fanconi avec myélose aplasique terminale. Arch Fr Pediatr 1957;14:415-22.

32 Francis RC, Moir RA, Swift PN. The value of splenectomy in Fanconi's anaemia. Arch Dis Child 1955;30: 439-44.

33 Cowdell RH, Phizackerley PJR, Pyke DA. Constitutional anemia (Fanconi syndrome) and leukemia in two brothers. Blood 1955;10:788-801.

34 Lynch MJ, Sherman L, Elliott FG. Fanconi's anemia (aplastic anemia with congenital abnormalities). Can Med Assoc J 1954;71:273-6.

35 Crisalli M, Sansone G. Constitutional infantile panmyelopathy with multiple malformations (Fanconi anemia). Helv Paediatr Acta 1952;7:299-308.

36 Delage JM. Pancytopénie familiale. Laval Med 1956;21: 334-50.

37 Ahjuja BK, Jain AM, Sethi AS. Fanconi's anemia. Indian J Pediatr 1969;36:284-90.

38 Bushkell LL, Kersey JH, Cervenka J. Chromosomal breaks in T and B lymphocytes in Fanconi's anaemia. Clin Genet 1976;9:583-7. 
39 Esparza A, Thompson WR. Familial hypoplastic anemia with multiple congenital anomalies. Report of 3 cases. Rhode Island Med J 1966;49:103-10.

40 McAlpine SG. Familial hypoplastic anaemia with congenital abnormalities (Fanconi's syndrome). Report of a case. Glasgow Med J 1954;153:46-50.

41 Meme JS, Oduori ML, Gripenberg U. Fanconi's aplastic anaemia: a case report of an affected African child and a review of the literature. East Afr Med J 1975;52:462-6.

42 Pedersen FK, Hertz H, Lundsteen C, Platz P, Thomsen M. Indication of primary immune deficiency in Fanconi's anaemia. Acta Paediatr Scand 1977;66:745-51.

43 Perkins J, Timson J, Emery AEH. Clinical and chromosomal studies in Fanconi's aplastic anaemia. $J$ Med Genet $1969 ; 6: 28-33$.

44 Cassimos C, Zannos L. Congenital hypoplastic anemia associated with multiple developmental defects (Fanconi's syndrome). Am J Dis Child 1952;84:347-50.

45 Goldstein R. Hypoplastic anemia with multiple congenital anomalies (Fanconi syndrome). Am J Dis Child 1955;89:168-22.

46 Chappell BS. Transposition of external genitalia in a case with Fanconi type deformity. J Urol 1958;79:115-8.

47 Auerbach AD, Warburton D, Bloom AD, Chaganti RSK. Prenatal detection of the Fanconi anemia gene by cytogenetic methods. Am J Hum Genet 1979;31:77-81.

48 Aymé S, Mattei JF, Mattei MG, Aurran Y, Giraud F. Nonrandom distribution of chromosome breaks in cultured lymphocytes of normal subjects. Hum Genet 1976;31:161-75.

49 Dutrillaux B, Couturier J, Viegas-P'equignot E, Schaison G. Localization of chromatid breaks in Fanconi's anemia, using three consecutive stains. Hum Genet 1977; 37:65-71.

50 Von Koskull H, Aula P. Distribution of chromosome breaks in measles, Fanconi's anemia, and controls. Hereditas 1977;87:1-10.

51 Von Koskull H, Aula P. Non-random distribution of chromosome breaks in Fanconi's anaemia. Cytogenet Cell Genet 1973;12:423-34.

52 Nathanson SD, van Biljon SM, Kallmeyer J. Constitutional aplastic anemia (Fanconi type): case presentation and review of the literature. $S$ Afr Med J 1968;42: 1159-61.

53 Altay C, Sevgi Y, Pirnar T. Letter. Fanconi's anemia in offspring of patient with congenital radial and carpal hypoplasia. $N$ Engl J Med 1975;293:151-2.

54 Estren S, Dameshek W. Familial hypoplastic anemia of childhood. Report of 8 cases in $\mathbf{2}$ families with beneficial effect of splenectomy in one case. Am J Dis Child 1947 73:671-87.

Requests for reprints to Dr F C Fraser, Division of Community Medicine, Health Sciences Centre, Memorial University, St John's, Newfoundland, Canada A1B 3V6. 